\title{
The effect of colostrum intake on osteoprotegerin and bone metabolic markers in the blood of newborn calves during the first week of life
}

\author{
Kaoru HATATE ${ }^{1,2)}$, Mitsunori KAYANO ${ }^{3)}$, Chiho KAWASHIMA ${ }^{4)}$, \\ Masaaki HANADA ${ }^{5)}$, Rodrigo C. BICALHO ${ }^{6)}$ and Norio YAMAGISHI ${ }^{1,2) *}$ \\ ${ }^{1)}$ Clinical Veterinary Science, United Graduate School of Veterinary Sciences, Gifu University, 1-1 Yanagido, \\ Gifu 501-1193, Japan \\ ${ }^{2)}$ Department of Veterinary Medicine, Obihiro University of Agriculture and Veterinary Medicine, \\ 2-11, Inada, Obihiro, Hokkaido 080-8555, Japan \\ ${ }^{3)}$ Research Center for Global Agromedicine, Obihiro University of Agriculture and Veterinary Medicine, \\ 2-11, Inada, Obihiro, Hokkaido 080-8555, Japan \\ 4) Field Center of Animal Science and Agriculture, Obihiro University of Agriculture and Veterinary Medicine, \\ 2-11, Inada, Obihiro, Hokkaido 080-8555, Japan \\ ${ }^{5)}$ Department of Life Science and Agriculture, Obihiro Univerisity of Agriculture and Veterinary Medicine, \\ 2-11, Inada, Obihiro, Hokkaido 080-8555, Japan \\ 6) Department of Population Medicine and Diagnostic Sciences, Cornell University, College of Veterinary \\ Medicine, Ithaca, NY 14853, U.S.A.
}

J. Vet. Med. Sci.

81(1): 15-21, 2019

doi: 10.1292/jvms.18-0453

Received: 1 August 2018 Accepted: 26 October 2018 Published online in J-STAGE: 7 November 2018

\begin{abstract}
The aim of this study was to elucidate the bone metabolic status after taking colostrum in newborn calves. Fourteen neonatal calves were randomly allocated to two groups fed either unheated or heated $\left(60^{\circ} \mathrm{C}, 30 \mathrm{~min}\right)$ colostrum three times on the first day $(2$ l every 10 $\mathrm{hr} ; 6 /$ in total). Heat treatment on colostrum was to reduce the bone metabolic markers assumed as heat-sensitive. The concentrations of four bone metabolic markers (the enzymes from bone cells or the bone collagen fragments) and a bone protective protein, osteoprotegerin (OPG), were measured in the blood of calves during a week after the birth and in the colostrum. The colostral concentrations of four bone metabolic markers were reduced by heating. Then those circulatory markers peaked after colostrum intake in the calves fed unheated colostrum; whereas those fed heated colostrum did not show such changes. However, the plasma tartrate resistant acid phosphatase 5b (TRAP5b) activity was transiently increased after taking colostrum in both groups. Meanwhile, heating did not decrease colostral OPG and there was no significant rise in the serum OPG concentrations after the first colostrum intake in both groups. The study revealed that the blood concentrations of studied bone metabolic markers depended on those colostral values except for TRAP5b. Based on the plasma TRAP5b changes, accelerated formation of premature osteoclast cells may be induced by colostrum intake. Meanwhile, colostral OPG absorption is less likely to impact on its circulating levels.

KEY WORDS: bone metabolism, colostrum, newborn calf, osteoclast, osteoprotegerin
\end{abstract}

Fetal blood calcium (Ca) levels are maintained by maternal $\mathrm{Ca}$ transport via the placenta during the late stages of pregnancy $[23,39]$. Neonates suddenly lose this Ca supply when the umbilical cord is cut at birth; then, colostral Ca absorption and bone resorption become important for the maintenance of Ca homeostasis [24]. We recently reported that four circulating bone metabolic markers temporally peaked around a half-day of life in newborn calves [19]. Those markers were the enzymes secreted from bone cells or the bone collagen fragments as follows: tartrate resistant acid phosphatase 5b (TRAP5b) was produced from osteoclast and its activity in blood was known to correlate with the osteoclast number [1]. N-telopeptide of type I collagen (NTx) is the end-product of bone collagen degradation [7, 18]. Alkaline phosphatase (ALP) presents in many types of mammalian tissues and bone-specific ALP (BAP) is produced by activated osteoblasts [32], and BAP is predominant in one of ALP isozymes in growing animals [2]. Our data suggested that the increase in bone metabolic markers was related to the colostrum intake [19], although the 
colostral concentrations of those have not been determined.

Recently, it has been reported that osteoprotegerin (OPG) inhibits both differentiation and activation of osteoclasts as a soluble decoy receptor of the receptor activator of nuclear factor-kappa B (RANK) ligand (RANKL) [33]. Coupling of RANKL and RANK on the immature osteoclasts induces osteoclastic cell differentiation, called osteoclastogenesis [4, 42]. Furthermore, OPG plays a protective role on bone resorption by blocking the interaction of RANK and RANKL [20, 38]. Interestingly, it has been reported that human milk-derived OPG permeated through the gastrointestinal tract into the circulatory system of rat pups and it also inhibited the bone resorption in vitro [41].

Some milk proteins are known to affect bone growth in infants, such as lactoferrin [26], leptin [5, 30] and insulin-like growth factor-1 [22]. Therefore, we hypothesized that maternal OPG and bone metabolic markers were transported to calves by colostrum and had a certain effect on neonatal bone metabolism soon after birth. In the present study, we evaluated the changes in concentrations of OPG and four bone metabolic markers in the blood of newborn calves fed unheated and heated colostrum during a week after birth. Heat treatment of colostrum was performed to decrease the colostral concentrations of bone metabolic markers, since some of those were assumed to be heat-sensitive and inactivated by heating $[6,16,17,25]$. The final goal of this study was to evaluate the effect of colostrum intake on the changes of those markers in the blood of newborn calves during the first week of life to speculate the role of colostrum on the neonatal bone metabolism.

\section{MATERIALS AND METHODS}

\section{Study design}

This study included 14 female Holstein Friesian newborn singleton calves, born at the Obihiro University of Agriculture and Veterinary Medicine (OUAVM) farm. All calves were fed good quality of colostrum defined by its density higher than 1,044 kg/ $\mathrm{m}^{3}$ [13]. Each pack of colostrum from an individual cow was stored at $-20^{\circ} \mathrm{C}$ and melted with warm water before feeding. The calves were randomly allocated to two groups, receiving different packs of unheated (UH group; $n=7)$, or heated (HT group; $\mathrm{n}=7$ ) colostrum during the first day of life. Heat treatment of colostrum was conducted before feeding $\left(60^{\circ} \mathrm{C}\right.$ for $\left.30 \mathrm{~min}\right)$ [11]. The calves were separated from the dams immediately after birth, and fed colostrum three times on the first day $(2 l$ every $10 \mathrm{hr} ; 6 l$ in total). All calves were fed the first colostrum within an hour after birth. From the second day, $2 l$ of milk replacer (calf top EX; Zenrakuren, Tokyo, Japan) was fed twice a day. The study protocol was approved by OUAVM Laboratory Animal Care and Use Committee (\#28-157).

\section{Sample collection}

Blood samples were withdrawn from the jugular veins of calves immediately before the first colostrum feeding (pre-feeding), every $10 \mathrm{hr}$ after the first blood collection $(10,20,30$, and $40 \mathrm{hr}$ ) since the rapid changes of bone metabolic markers were observed within two days after birth [19]. For the basis of comparison, additional blood sampling was conducted in the morning of the seventh day (d 7). The blood samples were withdrawn into $5 \mathrm{ml}$ plain and $7 \mathrm{~m} l$ heparinized vacuum collection tubes (Venoject II; Terumo, Tokyo, Japan). Immediately after blood sampling, the calves were bottle-fed with colostrum (pre-feeding, 10 and $20 \mathrm{hr}$ ), and milk replacer $(30$ and $40 \mathrm{hr}$ ). A portion $(50 \mathrm{ml})$ of each colostrum sample was retained for testing. Samples were centrifuged ( $15 \mathrm{~min}$ at $1,680 \times \mathrm{g}$ for blood, and $20 \mathrm{~min}$ at $1,500 \times \mathrm{g}$ for colostrum). The serum and plasma were stored at $-80^{\circ} \mathrm{C}$, and the intermediate layer of colostrum was stored at $-20^{\circ} \mathrm{C}$ prior to analysis.

\section{Biochemical analysis of blood and milk}

The concentrations of OPG and bone markers (TRAP5b, NTx, ALP, and BAP) in each colostrum sample were analyzed. For the heated colostrum, the concentrations were measured before and after heating (pre- and post-HT colostrum). Changes in blood OPG and the bone metabolic markers were measured during the first week of life. The serum concentrations of immunoglobulin $\mathrm{G}$ (IgG), total protein (TP), Ca, and inorganic phosphorus (iP) were also analyzed on the day of birth (pre-feeding, $10 \mathrm{and} 20 \mathrm{hr}$ ).

OPG concentrations in the serum and milk were measured by a quantitative competitive enzyme-linked immunosorbent assay (ELISA) coated with an OPG-specific antibody, using a commercial ELISA kit (Bovine OPG ELISA kit; NeoScientific, Cambridge, MA, U.S.A.). The antibody indicated cross-reactivity with the bovine OPG. After incubation with OPG-horseradish peroxidase $\left(37^{\circ} \mathrm{C}, 60 \mathrm{~min}\right)$, the absorbance was measured at $450 \mathrm{~nm}$ (ALVO MX/ Light 1420; PerkinElmer, Waltham, MA, U.S.A.).

A fluorometric assay of TRAP5b activity in the plasma and milk was conducted via a modified version of the Janckila method $[21,27]$, which uses naphthol-ASBI-phosphate (N-ASBI-P; Wako Pure Chemical Industries, Osaka, Japan) as a substrate. A $10 \mu l$ sample of plasma was incubated with $0.25 \mathrm{mmol} / l$ of N-ASBI-P reaction solution containing $100 \mathrm{mmol} / l$ sodium acetate and 50 $\mathrm{mmol} / \mathrm{l}$ sodium tartrate (Wako Pure Chemical Industries, Osaka, Japan) at $37^{\circ} \mathrm{C}$ for $30 \mathrm{~min}$, and the fluorescence was detected with an emission wavelength of $535 \mathrm{~nm}$ and an excitation wavelength of $405 \mathrm{~nm}$.

The NTx concentrations in the serum and milk were quantified by a competitive ELISA, which is cross-reactive with bovine NTx, using a commercial kit (Osteomark NTx serum; Abbott, Abbott Park, IL, U.S.A.). The absorbance was read at $450 \mathrm{~nm}$.

The ALP and BAP concentrations in the plasma and milk were determined using a commercial ALP kit (LabAssay ALP kit; Wako Pure Chemical Industries, Osaka, Japan). During incubation at $37^{\circ} \mathrm{C}$ for 15 min, the enzymes reacted with p-nitrophenylphosphate (PNPP), and the p-nitrophenol product was measured at $405 \mathrm{~nm}$. Based on the thermal instability of BAP, the BAP concentration was determined by subtracting the thermally-insensitive ALP concentration from the intact ALP concentration [28]. 
Table 1. Results of biochemical data in colostrum (mean $\pm \mathrm{SEM}$ )

\begin{tabular}{lccc}
\hline & Unheated & Pre-HT & Post-HT \\
\hline OPG $(n \mathrm{~g} / \mathrm{m} l)$ & $8.8 \pm 5.2$ & $7.2 \pm 1.5$ & $4.2 \pm 1.1$ \\
TRAP5b $(\mathrm{U} / l)$ & $3.0 \pm 0.2$ & $\left.4.3 \pm 1.0^{\mathrm{a}}\right)$ & $\left.0.6 \pm 0.03^{\mathrm{b}}\right)$ \\
NTx $(\mathrm{nmol} \mathrm{BCE} / l)$ & $37.9 \pm 7.8$ & $\left.31.9 \pm 1.7^{\mathrm{c}}\right)$ & $\left.21.6 \pm 1.7^{\mathrm{d}}\right)$ \\
ALP $(\mathrm{U} / l)$ & $1,655.2 \pm 55.9$ & $\left.1,666.5 \pm 60.9^{\mathrm{c}}\right)$ & $\left.359.2 \pm 92.9^{\mathrm{d}}\right)$ \\
BAP $(\mathrm{U} / l)$ & $542.7 \pm 22.8$ & $441.2 \pm 108.9$ & $120.0 \pm 75.6$ \\
\hline
\end{tabular}

a, b) Means in the same row with different superscripts were significantly different $(P<0.05)$. c, d) Means in the same row with different superscripts were significantly different $(P<0.01)$. Unheated: unheated colostrum fed to UH group ( $\mathrm{n}=7)$, Pre-HT: colostrum for the HT group prior to heat treatment $(n=6)$, Post-HT: colostrum for the HT group after heat treatment $(n=6), \mathrm{OPG}$; osteoprotegerin, TRAP5b; tartrate-resistant acid phosphatase 5b, NTx; N-telopeptide of type I collagen, ALP; alkaline phosphatase, BAP; bone-specific alkaline phosphatase.

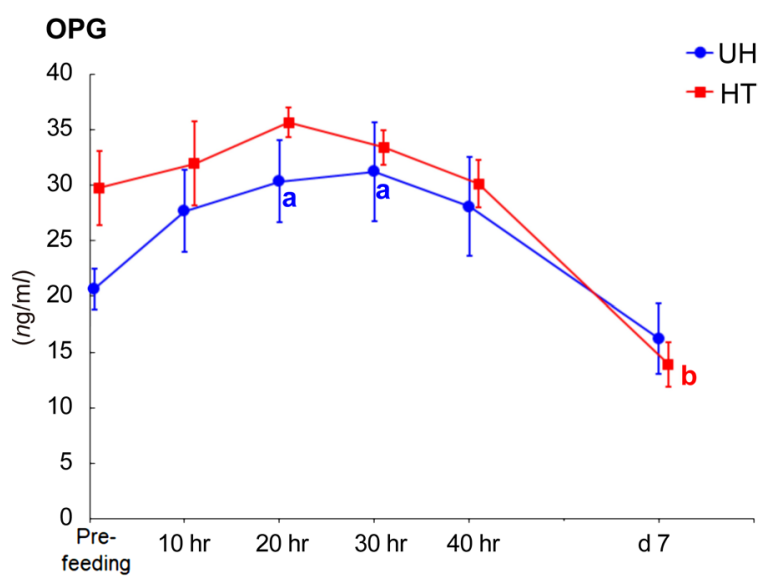

Fig. 1. Changes in osteoprotegerin (OPG) blood concentrations in neonatal calves during the first week of life. The blue circles represent the blood concentrations of the calves fed unheated colostrum $(\mathrm{UH}, \mathrm{n}=7$ ); the red squares represent the blood concentrations of the calves fed heated colostrum (HT, n=7). The OPG concentrations of the UH group showed a significant increase at 20 and $30 \mathrm{hr}$ compared to pre-feeding values (a: $P<0.05$ ). The OPG levels of the HT group showed a significant reduction at day 7 (d 7$)$ compared to pre-feeding values (b: $P<0.01$ ).

Serum IgG concentrations were determined using a commercial ELISA kit (Fast-ELISA; RD Biotech, Besançon, France) that had cross-reactivity with bovine IgG. Serum concentrations of TP, Ca, and iP were measured by enzymatic analysis, using a blood biochemical auto-analyzer (TBA-120FR; Canon Medical Systems, Otawara, Japan).

\section{Statistical analysis}

All numerical data are presented as means with standard error of the mean (SEM). The difference of body weight (BW) at birth between groups was compared by Student $t$-test. Comparisons of colostral concentrations were performed using unpaired $t$-test for unheated vs. pre-HT and paired $t$-test for pre-HT vs. post-HT. The mixed-model repeated-measures analysis of covariance (ANCOVA) of the first-order ante dependence (ANTE) structure was applied to study the effect of heat treatment on blood biochemistry, with fixed effects (group, time, and group $\times$ time), and the random effect of individual calves. As a covariate, the blood concentration at pre-feeding was set as the baseline [37]. Comparisons between and within the groups were conducted using Tukey's post-hoc test. The data analysis was conducted using SAS enterprise guide software (ver. 7.1; SAS Institute Inc., Cary, NC, U.S.A.). Statistically significant results were characterised by $P<0.05$.

\section{RESULTS}

\section{$B W$ at birth}

The average BW of the calves was $42.5 \mathrm{~kg}$. There was no significant difference in BW between groups (UH: $41.8 \pm 1.8 \mathrm{~kg}, \mathrm{HT}$ : $43.1 \pm 1.5 \mathrm{~kg})$.

\section{Effect of heat treatment on OPG and four bone metabolic markers in the colostrum}

Table 1 shows the effect of heat treatment on OPG and bone metabolic marker concentrations in colostrum. There was no significant difference in OPG values between the pre-HT and post-HT $(P=0.09)$. On the other hand, after heating, the colostral TRAP5b, NTx, and ALP concentrations were significantly reduced. Although the mean BAP concentration of post-HT was about one-third of those of pre-HT, there were no significant changes $(P=0.08)$ due to high variability. The levels of bone markers and OPG of milk replacer were lower than those of colostrum (TRAP5b; $0.38 \mathrm{U} / l$, NTx; 9.1 nmol BCE/l, ALP; 512.8 U/l, BAP; 308.7 $\mathrm{U} / l$, OPG; $1.34 \mathrm{ng} / \mathrm{m} l)$.

\section{Blood biochemical data in the newborn calves}

The data indicated no significant differences in serum OPG concentrations between groups during the experimental period (Fig. 1). In the UH group, serum OPG concentrations significantly increased at 20 and $30 \mathrm{hr}(30.4 \pm 3.7 \mathrm{and} 31.2 \pm 4.5 \mathrm{ng} / \mathrm{ml}$, respectively), compared to pre-feeding values $(20.7 \pm 1.8 \mathrm{ng} / \mathrm{ml})$. For the HT group, there were no significant changes to OPG concentrations during the first 2 days $(29.8-35.6 \mathrm{ng} / \mathrm{m} l)$, but OPG concentrations dropped significantly at $\mathrm{d} 7(13.9 \pm 2.0 \mathrm{ng} / \mathrm{ml})$, 

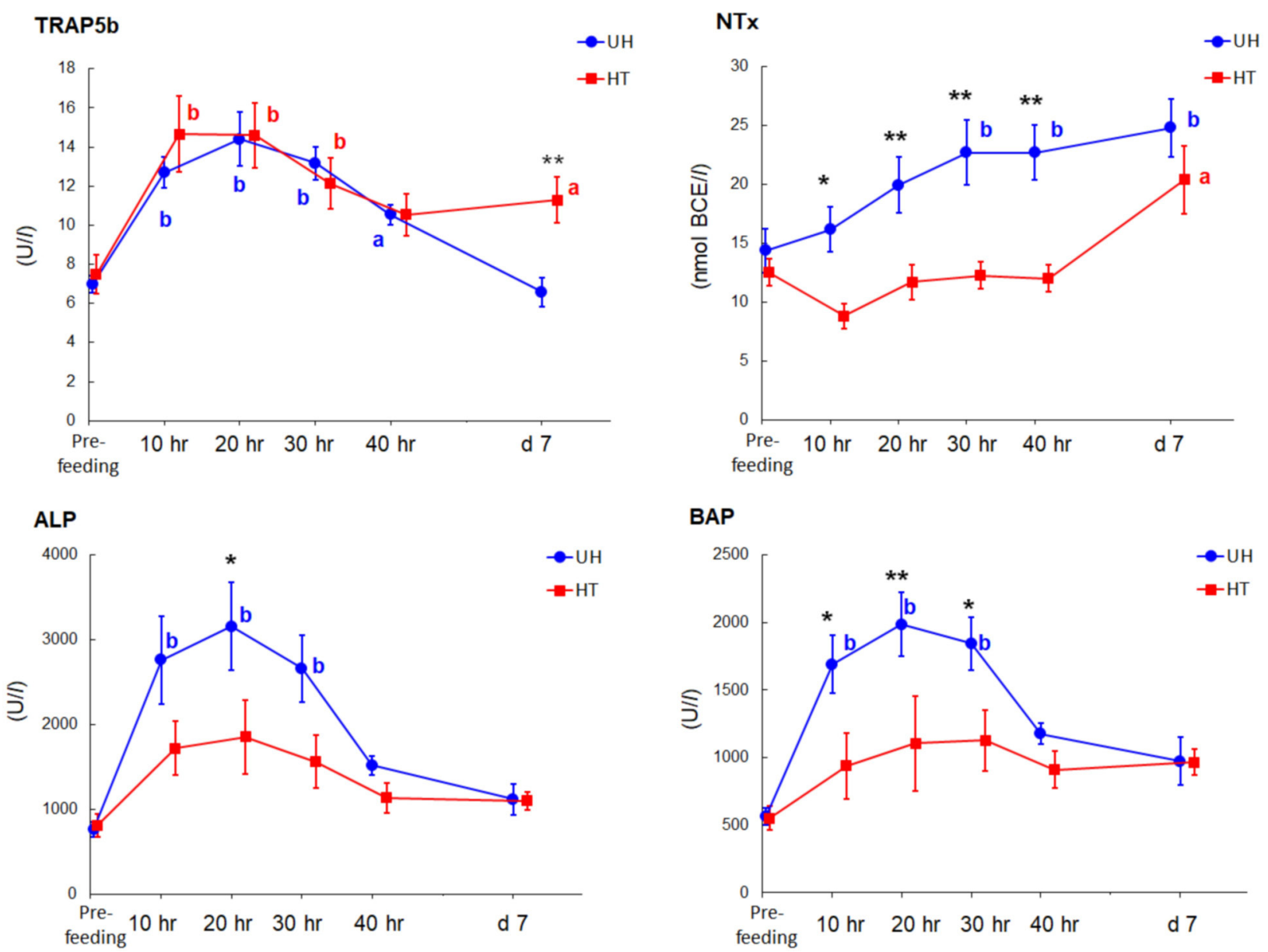

Fig. 2. Changes in blood concentrations of four bone metabolic markers, tartrate-resistant acid phosphatase 5b (TRAP5b), N-telopeptide of type I collagen (NTx), alkaline phosphatase (ALP), and bone-specific alkaline phosphatase (BAP), in neonatal calves during the first week of life. The blue circles represent the blood concentrations of the calves fed unheated colostrum (UH, $n=7)$; the red squares represent the blood concentrations of the calves fed heated colostrum (HT, $\mathrm{n}=7$ ). For NTx, ALP and BAP, significant differences were evident between groups $(* *: P<0.01$, *: $P<0.05$ ). The UH group showed significant increases in all four markers compared to the value of each pre-feeding value (b: $P<0.01$, a: $P<0.05)$. The HT group showed significant increases in TRAP5b and NTx concentrations compared to pre-feeding values (b: $P<0.01$, a: $P<0.05$ ).

compared to pre-feeding values $(29.8 \pm 3.3 \mathrm{ng} / \mathrm{m} l)$.

Figure 2 shows the changes in concentrations of four bone markers in the blood of the calves. The plasma TRAP5b concentrations during the first 2 days were comparable between groups, but there were significant differences at d 7 (UH: $6.6 \pm$ 0.74 vs. HT: $11.3 \pm 1.2 \mathrm{U} / \mathrm{l}$ ). The plasma TRAP5b concentrations in both groups increased significantly during the first 2 days (UH: 10.5-14.4 U/l, HT: 10.5-14.7 U/l), compared to the pre-feeding values (UH: $7.0 \pm 0.42 \mathrm{U} / l, \mathrm{HT}: 7.5 \pm 1.0 \mathrm{U} /$ ). The serum NTx concentrations from 10 to $40 \mathrm{hr}$ were significantly different between the two groups. The UH group exhibited a significant increase in serum NTx from $30 \mathrm{hr}$ to $\mathrm{d} 7(22.7-24.8 \mathrm{nmol} \mathrm{BCE} / l)$, compared to the pre-feeding values $(14.4 \pm 1.9 \mathrm{nmol} \mathrm{BCE} / \mathrm{l})$. Meanwhile, NTx concentrations in the HT group did not significantly increase during the first 2 days, but the mean concentrations at $\mathrm{d} 7$ were significantly higher compared to the pre-feeing values $(20.4 \pm 2.9$ vs. $12.5 \pm 1.2 \mathrm{nmol} \mathrm{BCE} / l)$. The plasma ALP activities at 20 $\mathrm{hr}$ in the UH group were significantly higher than those in the HT group. The UH group showed a significant increase in plasma ALP activities from 10 to $30 \mathrm{hr}(2,660-3,159 \mathrm{U} / l)$ compared to pre-feeding values $(769 \pm 90.4 \mathrm{U} / l)$. The HT group did not show any significant differences in plasma ALP activities during the 7-day period $(816-1,855 \mathrm{U} / l)$. The plasma BAP activities in the UH group were significantly higher from 10 to $30 \mathrm{hr}$ compared to those in the HT group. The UH group exhibited a significant increase in plasma BAP activities from 10 to $30 \mathrm{hr}(1,690-1,986 \mathrm{U} / l)$ compared to pre-feeding values $(563 \pm 61.8 \mathrm{U} / l)$, whereas the HT group did not exhibit any significant changes in plasma BAP activities during the experimental period (553-1,128 U/l).

Table 2 shows the changes in serum TP, IgG, and mineral ( $\mathrm{Ca}$ and iP) concentrations over the first day; there were no significant differences between groups in each time-point. Serum IgG and TP concentrations exhibited a significant increase after colostrum feeding. The serum $\mathrm{Ca}$ and $\mathrm{iP}$ concentrations in both groups remained constant. 
Table 2. Results of blood biochemistry in newborn calves (mean \pm SEM)

\begin{tabular}{lcccc}
\hline & & Pre-feeding & $10 \mathrm{hr}$ & $20 \mathrm{hr}$ \\
\hline $\mathrm{IgG}(\mathrm{g} / l)$ & $\mathrm{UH}$ & $0.0 \pm 0.0^{\mathrm{a})}$ & $9.1 \pm 1.1^{\mathrm{b})}$ & $\left.15.5 \pm 2.2^{\mathrm{b}}\right)$ \\
& $\mathrm{HT}$ & $0.0 \pm 0.0^{\mathrm{a})}$ & $12.7 \pm 2.2^{\mathrm{b})}$ & $20.6 \pm 2.7^{\mathrm{b})}$ \\
\hline $\mathrm{TP}(\mathrm{g} / l)$ & $\mathrm{UH}$ & $42.4 \pm 1.0^{\mathrm{a})}$ & $53.5 \pm 1.5^{\mathrm{b})}$ & $\left.59.9 \pm 1.8^{\mathrm{b}}\right)$ \\
& $\mathrm{HT}$ & $46.0 \pm 1.4^{\mathrm{a})}$ & $56.6 \pm 2.7^{\mathrm{b})}$ & $62.5 \pm 2.7^{\mathrm{b})}$ \\
\hline $\mathrm{Ca}(\mathrm{mmol} / l)$ & $\mathrm{UH}$ & $2.9 \pm 0.08$ & $2.9 \pm 0.04$ & $2.8 \pm 0.05$ \\
& $\mathrm{HT}$ & $3.0 \pm 0.08$ & $2.9 \pm 0.08$ & $2.9 \pm 0.06$ \\
\hline $\mathrm{iP}(\mathrm{mmol} / l)$ & $\mathrm{UH}$ & $1.8 \pm 0.01$ & $2.1 \pm 0.03$ & $2.2 \pm 0.07$ \\
& HT & $2.1 \pm 0.07$ & $2.2 \pm 0.08$ & $2.3 \pm 0.14$ \\
\hline
\end{tabular}

a, b) Means in the same row with different superscripts were significantly different $(P<0.01)$ Pre-feeding: immediately before the first colostrum feeding, $10 \mathrm{hr}$ : $10 \mathrm{hr}$ after the first colostrum feeding, $20 \mathrm{hr}$ : $20 \mathrm{hr}$ after the first colostrum feeding, UH; calves fed unheated colostrum ( $(n=7), H T$; calves fed heated colostrum ( $n=7), \operatorname{IgG}$; immunoglobulin $\mathrm{G}, \mathrm{Ca}$; calcium, iP; inorganic phosphorus.

\section{DISCUSSION}

We explored bone metabolic status by comparing the blood concentrations of OPG and four bone metabolic markers of newborns fed two different types of colostrum. Adequate passive transfer of $\mathrm{IgG}$ was defined as serum $\mathrm{IgG}$ levels exceeding $10 \mathrm{~g} / \mathrm{l}$ or serum TP levels exceeding $52 \mathrm{~g} / l$ [40]. In our experiment, all calves satisfied at least one of these criteria at day 1 . Furthermore, the serum concentrations of $\mathrm{Ca}$ and iP did not differ between groups, suggesting that appropriate mineral transport via colostrum feeding was accomplished in both groups. It has been shown that, during the first $24 \mathrm{hr}$ of life, calves exhibit non-selective absorption through the intestines via enterocytic pinocytosis; the highest rate of IgG absorption begins immediately after the first feeding, and the rate then decreases over the next $10 \mathrm{hr}$ [10, 34-36]. In the present study, heat treatment reduced bone metabolic markers in the colostrum and the blood concentrations of NTx, ALP and BAP increased over $40 \mathrm{hr}$ after the first colostrum absorbed in the UH group; but not in the HT group. Accordingly, we could attenuate the effect of those colostral values on the blood concentrations when comparing two groups of calves.

Heat treatment reduced enzyme activities in colostrum. Nevertheless, the plasma TRAP5b concentrations peaked during the first two days in both groups; suggested the accelerated endogenous secretion of TRAP5b after the first colostrum absorption. Oliveira et al. [31] found that nanoparticles derived from bovine milk enhances the differentiation of immature TRAP5b-positive osteoclasts. Despite heated colostrum contained almost double the pre-feeding levels of the serum NTx (21.6 \pm 1.7 vs. $12.5 \pm 1.1$ $\mathrm{nmol} \mathrm{BCE} / l$ ), its changes remained low in the HT group during two days after birth with less colostral NTx absorption. Unlike enzyme-type bone metabolic markers, bone protein fragment of NTx is against further proteolysis in circulation and excreted into urine [18]. In neonatal calves, it probably accumulated in circulation and reached the same level as the UH group at d 7 due to the low clearance rate of immature kidney over the first week of life [8]. For all that, we found the non-negligible effect of colostral NTx, ALP and BAP on those circulating concentrations due to the distinct blood fluctuation patterns between two groups.

The present study claimed that OPG was heat-resistant protein in colostrum and serum OPG concentrations in newborn calves did not increase after the first colostrum intake in both groups. Naylor et al. [29] reported that the OPG concentration in human milk is 200-fold higher than that found in maternal and neonatal serum. Unlike their finding, raw bovine colostrum contained comparable amounts of OPG $(\mathrm{n}=13,7.79 \pm 2.6 \mathrm{ng} / \mathrm{m} l)$ to the intact level of neonatal circulation $(25.2 \pm 2.1 \mathrm{ng} / \mathrm{m} l)$. The study indicated serum OPG concentrations during 2 days after birth were high compared to those at $\mathrm{d} 7$, especially in calves fed heated colostrum. From our observation, anti-resorbing activity of colostral OPG may have less impact on neonatal bone metabolism. Newborn calves are born with more developed neuromuscular function compared to human babies because they are required to walk a few hours after birth [9]. It has been suggested that abundant OPG in human milk may have a potential role in supporting infants who are born at relatively early stage of development compared to bovine newborns [9, 29]. In the future, additional analysis of blood RANKL concentration would help evaluate the balance of bone formation and resorption in neonatal calves.

Colostrum is important for newborn calves to supply immunity, nutrients and growth factors, as well as to promote development of the gastrointestinal tracts $[3,14]$. Timing and amount of the colostrum feeding have a significant effect on daily weight gain $[12,43]$. Interestingly, the plasma TRAP5b fluctuation suggested that the colostrum intake promoted a rapid osteoclast formation, however, bovine milk diminished the bone resorption area in vitro [41], which may be induced by reduction of the matured osteoclast activity [31]. Moreover, we found that a large amount of colostral ALP and BAP were transferred into neonatal circulation. A potential function of these alkaline phosphatase in bone formation is still controversial, although these enzymes may facilitate extracellular mineralization [15]. The implication that the colostrum absorption affects neonatal bone metabolism warrants the further research regarding the longitudinal evaluation of colostrum intake on bone growth of calves.

This study evaluated the changes of bone metabolic markers in the blood of dairy calves after taking colostrum based on OPG and four bone metabolic markers during the first week of life. As we suggested in the previous study [19], the blood changes of NTx, ALP and BAP were highly associated with those colostral values. However, the rapid increase in the plasma TRAP5b activity 
presumably indicated the endogenous proliferation of osteoclasts. Overall, the finding from this study implied that colostrum intake stimulated the osteoclastogenesis, while bone breakdown activity remained unknown in this period. We also found that the intestinal absorption of bone protective proteins of OPG via colostrum seemed limited relative to the neonatal circulating levels. Nevertheless, the further experiment is required in order to evaluate the innate bone metabolic activity, such as feeding bone marker-free colostrum to eliminate the effect of colostrum absorption. Taking our findings into account, it would be the further concern for the physiological significance of colostrum intake on skeletal growth of dairy cows.

ACKNOWLEDGMENTS. We would appreciate Dr. Acosta Ayala Thomas Javier, Mr. Akihiro Fujieda, Mr. Aung Htun and all staffs of the Field Center of Animal Science and Agriculture, OUAVM, for their supports. This research did not receive any specific grant from funding agencies in the public, commercial, or not-for-profit sectors.

\section{REFERENCES}

1. Alatalo, S. L., Halleen, J. M., Hentunen, T. A., Mönkkönen, J. and Väänänen, H. K. 2000. Rapid screening method for osteoclast differentiation in vitro that measures tartrate-resistant acid phosphatase 5b activity secreted into the culture medium. Clin. Chem. 46: 1751-1754. [Medline]

2. Allen, M. J. 2003. Biochemical markers of bone metabolism in animals: uses and limitations. Vet. Clin. Pathol. 32: 101-113. [Medline] [CrossRef]

3. Blum, J. W. and Hammon, H. 2000. Colostrum effects on the gastrointestinal tract, and on nutritional, endocrine and metabolic parameters in neonatal calves. Livest. Prod. Sci. 66: 151-159. [CrossRef]

4. Boyle, W. J., Simonet, W. S. and Lacey, D. L. 2003. Osteoclast differentiation and activation. Nature 423: 337-342. [Medline] [CrossRef]

5. Casabiell, X., Piñeiro, V., Tomé, M. A., Peinó, R., Diéguez, C. and Casanueva, F. F. 1997. Presence of leptin in colostrum and/or breast milk from lactating mothers: a potential role in the regulation of neonatal food intake. J. Clin. Endocrinol. Metab. 82: 4270-4273. [Medline] [CrossRef]

6. Claeys, W. L., Ludikhuyze, L. R., van Loey, A. M. and Hendrickx, M. E. 2001. Inactivation kinetics of alkaline phosphatase and lactoperoxidase, and denaturation kinetics of $\beta$-lactoglobulin in raw milk under isothermal and dynamic temperature conditions. J. Dairy Res. 68: 95-107. [Medline] [CrossRef]

7. Clemens, J. D., Herrick, M. V., Singer, F. R. and Eyre, D. R. 1997. Evidence that serum NTx (collagen-type I N-telopeptides) can act as an immunochemical marker of bone resorption. Clin. Chem. 43: 2058-2063. [Medline]

8. Dratwa, A. 2006. Atrial natriuretic peptide and renal haemodynamics in newborn calves. Acta Vet. Brno 75: 477-483. [CrossRef]

9. Dunsworth, H. M., Warrener, A. G., Deacon, T., Ellison, P. T. and Pontzer, H. 2012. Metabolic hypothesis for human altriciality. Proc. Natl. Acad. Sci. U.S.A. 109: 15212-15216. [Medline] [CrossRef]

10. Elisondo-Salazar, J. A. and Heinrichs, A. J. 2008. Review: heat treating bovine colostrum. T PAS 24: 530-538.

11. Elizondo-Salazar, J. A. and Heinrichs, A. J. 2009. Feeding heat-treated colostrum or unheated colostrum with two different bacterial concentrations to neonatal dairy calves. J. Dairy Sci. 92: 4565-4571. [Medline] [CrossRef]

12. Faber, S. N., Faber, N. E., McCauley, T. C. and Ax, R. L. 2005. Case study: effects of colostrum ingestion on lactational performance. Prof. Anim. Sci. 21: 420-425. [CrossRef]

13. Fleenor, W. A. and Stott, G. H. 1980. Hydrometer test for estimation of immunoglobulin concentration in bovine colostrum. J. Dairy Sci. 63: 973-977. [Medline] [CrossRef]

14. Godden, S. 2008. Colostrum management for dairy calves. Vet. Clin. North Am. Food Anim. Pract. 24: 19-39. [Medline] [CrossRef]

15. Golub, E. E. and Boesze-Battaglia, K. 2007. The role of alkaline phosphatase in mineralization. Curr. Opin. Orthop. 18: 444-448. [CrossRef]

16. Gursoy, U. K., Könönen, E., Huumonen, S., Tervahartiala, T., Pussinen, P. J., Suominen, A. L. and Sorsa, T. 2013. Salivary type I collagen degradation end-products and related matrix metalloproteinases in periodontitis. J. Clin. Periodontol. 40: 18-25. [Medline] [CrossRef]

17. Halleen, J. M., Tiitinen, S. L., Ylipahkala, H., Fagerlund, K. M. and Väänänen, H. K. 2006. Tartrate-resistant acid phosphatase 5b (TRACP 5b) as a marker of bone resorption. Clin. Lab. 52: 499-509. [Medline]

18. Hanson, D. A., Weis, M. A., Bollen, A. M., Maslan, S. L., Singer, F. R. and Eyre, D. R. 1992. A specific immunoassay for monitoring human bone resorption: quantitation of type I collagen cross-linked N-telopeptides in urine. J. Bone Miner. Res. 7: 1251-1258. [Medline] [CrossRef]

19. Hatate, K., Shinya, K., Matsuo-Sato, A., Sasaki, S., Devkota, B., Takahashi, M., Hirata, T. and Yamagishi, N. 2016. Changes in the plasma levels of several bone markers in newborn calves during the first two days of life. J. Vet. Med. Sci. 78: 337-340. [Medline] [CrossRef]

20. Hofbauer, L. C., Khosla, S., Dunstan, C. R., Lacey, D. L., Boyle, W. J. and Riggs, B. L. 2000. The roles of osteoprotegerin and osteoprotegerin ligand in the paracrine regulation of bone resorption. J. Bone Miner. Res. 15: 2-12. [Medline] [CrossRef]

21. Janckila, A. J., Takahashi, K., Sun, S. Z. and Yam, L. T. 2001. Naphthol-ASBI phosphate as a preferred substrate for tartrate-resistant acid phosphatase isoform 5b. J. Bone Miner. Res. 16: 788-793. [Medline] [CrossRef]

22. Kelly, O., Cusack, S. and Cashman, K. D. 2003. The effect of bovine whey protein on ectopic bone formation in young growing rats. Br. J. Nutr. 90: 557-564. [Medline] [CrossRef]

23. Kovacs, C. S. and Kronenberg, H. M. 1997. Maternal-fetal calcium and bone metabolism during pregnancy, puerperium, and lactation. Endocr. Rev. 18: 832-872. [Medline]

24. Kovacs, C. S. 2015. Calcium, phosphorus, and bone metabolism in the fetus and newborn. Early Hum. Dev. 91: 623-628. [Medline] [CrossRef]

25. Leikina, E., Mertts, M. V., Kuznetsova, N. and Leikin, S. 2002. Type I collagen is thermally unstable at body temperature. Proc. Natl. Acad. Sci. U.S.A. 99: 1314-1318. [Medline] [CrossRef]

26. Lorget, F., Clough, J., Oliveira, M., Daury, M. C., Sabokbar, A. and Offord, E. 2002. Lactoferrin reduces in vitro osteoclast differentiation and resorbing activity. Biochem. Biophys. Res. Commun. 296: 261-266. [Medline] [CrossRef]

27. Matsuo, A., Togashi, A., Sasaki, K., Devkota, B., Hirata, T. and Yamagishi, N. 2014. Diurnal variation of plasma bone markers in Japanese black calves. J. Vet. Med. Sci. 76: 1029-1032. [Medline] [CrossRef]

28. Mohebbi, A., Khaghani, A. and Mohammadnia, A. 2010. Bone-specific alkaline phosphatase activity in dairy cows. Comp. Clin. Pathol. 19: 33-36. [CrossRef]

29. Naylor, K. E., Rogers, A., Fraser, R. B., Hall, V., Eastell, R. and Blumsohn, A. 2003. Serum osteoprotegerin as a determinant of bone metabolism in a longitudinal study of human pregnancy and lactation. J. Clin. Endocrinol. Metab. 88: 5361-5365. [Medline] [CrossRef]

30. Ogueh, O., Sooranna, S., Nicolaides, K. H. and Johnson, M. R. 2000. The relationship between leptin concentration and bone metabolism in the human fetus. J. Clin. Endocrinol. Metab. 85: 1997-1999. [Medline] [CrossRef] 
31. Oliveira, M. C., Di Ceglie, I., Arntz, O. J., van den Berg, W. B., van den Hoogen, F. H. J., Ferreira, A. V. M., van Lent, P. L. E. M. and van de Loo, F. A. J. 2017. Milk-derived nanoparticle fraction promotes the formation of small osteoclasts but reduces bone resorption. J. Cell. Physiol. 232: 225-233. [Medline] [CrossRef]

32. Seibel, M. J. 2005. Biochemical markers of bone turnover: part I: biochemistry and variability. Clin. Biochem. Rev. 26: 97-122. [Medline]

33. Simonet, W. S., Lacey, D. L., Dunstan, C. R., Kelley, M., Chang, M. S., Lüthy, R., Nguyen, H. Q., Wooden, S., Bennett, L., Boone, T., Shimamoto, G., DeRose, M., Elliott, R., Colombero, A., Tan, H.L., Trail, G., Sullivan, J., Davy, E., Bucay, N., Renshaw-Gegg, L., Hughes, T. M., Hill, D., Pattison, W., Campbell, P., Sander, S., Van, G., Tarpley, J., Derby, P., Lee, R. and Boyle, W. J. 1997. Osteoprotegerin: a novel secreted protein involved in the regulation of bone density. Cell 89: 309-319. [Medline] [CrossRef]

34. Stott, G. H., Marx, D. B., Menefee, B. E. and Nightengale, G. T. 1979. Colostral immunoglobulin transfer in calves I. Period of absorption. J. Dairy Sci. 62: 1632-1638. [Medline] [CrossRef]

35. Stott, G. H., Marx, D. B., Menefee, B. E. and Nightengale, G. T. 1979. Colostral immunoglobulin transfer in calves II. The rate of absorption. J. Dairy Sci. 62: 1766-1773. [Medline] [CrossRef]

36. Stott, G. H., Marx, D. B., Menefee, B. E. and Nightengale, G. T. 1979. Colostral immunoglobulin transfer in calves. III. Amount of absorption. J. Dairy Sci. 62: 1902-1907. [Medline] [CrossRef]

37. Sugiyama, K., Sakakibara, R., Tachimoto, H., Kishi, M., Kaga, T. and Tabata, I. 2010. Effect of acetic acid bacteria supplementation on muscle damage after moderate-intensity exercise. Anti-Aging Medicine 7: 1-6. [CrossRef]

38. Theill, L. E., Boyle, W. J. and Penninger, J. M. 2002. RANK-L and RANK: T cells, bone loss, and mammalian evolution. Annu. Rev. Immunol. 20: 795-823. [Medline] [CrossRef]

39. Tivane, C., Rodrigues, M. N., Favaron, P. O., Assis-Neto, A. C., Birgel-Jr, E. H. and Miglino, M. A. 2013. Mechanisms of calcium transport across the placenta Review. Open J. Anim. Sci. 3: 13-20. [CrossRef]

40. Tyler, J. W., Hancock, D. D., Parish, S. M., Rea, D. E., Besser, T. E., Sanders, S. G. and Wilson, L. K. 1996. Evaluation of 3 assays for failure of passive transfer in calves. J. Vet. Intern. Med. 10: 304-307. [Medline] [CrossRef]

41. Vidal, K., van den Broek, P., Lorget, F. and Donnet-Hughes, A. 2004. Osteoprotegerin in human milk: a potential role in the regulation of bone metabolism and immune development. Pediatr. Res. 55: 1001-1008. [Medline] [CrossRef]

42. Yavropoulou, M. P. and Yovos, J. G. 2008. Osteoclastogenesis—current knowledge and future perspectives. J. Musculoskelet. Neuronal Interact. 8: 204-216. [Medline]

43. Zanker, I. A., Hammon, H. M. and Blum, J. W. 2001. Activities of $\gamma$-glutamyltransferase, alkaline phosphatase and aspartate-aminotransferase in colostrum, milk and blood plasma of calves fed first colostrum at 0-2, 6-7, 12-13 and 24-25 h after birth. J. Vet. Med. A Physiol. Pathol. Clin. Med. 48: 179-185. [Medline] [CrossRef] 